\title{
The Role of New-Emerging Lands on Sources of Aeolian Sand Deposits Driven by Shrinking of the Urmia Salt Lake
}

\author{
Aliakbar Nazari Samani ( $\sim$ aknazari@ut.ac.ir) \\ University of Tehran \\ Leila Biabani \\ University of Tehran \\ Abolhassan Fathabadi \\ Gonbad Kavous University \\ Hassan Khosravi \\ University of Tehran \\ Robert James Wasson \\ James Cook University \\ Moslem Borji Hassangavyar \\ University of Tehran
}

\section{Research Article}

Keywords: Aeolian hazard, emerging geomorphological units, sand provenance uncertainty, Mixing Model

Posted Date: December 14th, 2021

DOI: https://doi.org/10.21203/rs.3.rs-1087192/v1

License: (9) This work is licensed under a Creative Commons Attribution 4.0 International License.

Read Full License 


\title{
1 The role of new-emerging lands on sources of aeolian sand 2 deposits driven by shrinking of the Urmia salt lake
}

\author{
Aliakbar Nazari Samani ${ }^{*}$, Leila Biabani' ${ }^{2}$, Abolhassan Fathabadi ${ }^{3}$, Hassan Khosravi ${ }^{4}$, Robert James Wasson ${ }^{5}$ \\ and Moslem Borji Hassangavyar ${ }^{6}$
}

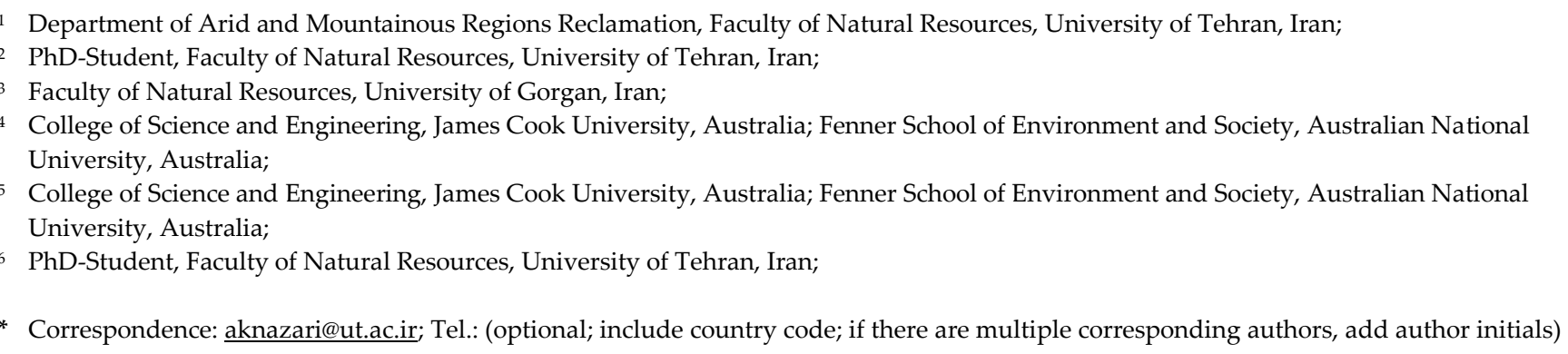

\section{Abstract:}

Urmia Lake, the largest saline lake in Iran and the Middle East, is located in the northwest of Iran, has shrunk over the past decades. The reduced water level has increased the area of dry land around the lake allowing new environmental hazard such as sand dunes encroachment, particularly on the western side of the lake. There are five terrain types that could contribute sediment to the dunes, and it is the main aim of this research to identify the contributions to the dunes of each terrain type. Fifteen surface samples were collected from the five most erodible terrain types and eight samples were collected from the dunes both in downwind and upwind directions from the lake, and major element components were measured using X-ray fluorescence (XRF). According to the Besler classification, all samples are in the saline class. Also, the chemical index of alteration (CIA) values in all samples were less than 50, indicating weak weathering. Based on multivariate statistical analysis, suitable tracers were selected and were imported to the sourcing equations. Quantification of uncertainty and the creation of two new fingerprinting models for aeolian sediments based on both Bayesian and GLUE procedures were used. The highest proportion comes from the salty and puffy lands $(44.2 \%)$ followed by salty polygon land $(23.5 \%)$, clay-salty areas, puffy-flaky lands $(7.01 \%)$, the terminus of the fine sandy alluvial fan $(13.2 \%)$, and clay-salty abandoned lands (12.1\%). It is concluded that if land managers use these results, they can more efficiently decrease the hazards posed by dune reactivation and migration though implementation of soil conservation on the affected lands around the dried lake.

Keywords: Aeolian hazard, emerging geomorphological units, sand provenance uncertainty, Mixing Model

\section{Introduction}

Wind erosion is one of the most important and complex geomorphic processes that cause's land degradation in arid, semi-arid and hyper-arid areas (Chappell et al.2019; Kasper-Zubillaga et al. 2007). About one-sixth of the world's population (Skidmore 200) lives in areas where there are mobile sand dunes with destructive effects on infrastructure and human activities. Sand dunes are easy to identify but the recognition of sand dune sources, for the design of soil conservation to slow dune construction and reduce mobility, requires detailed information (Gholami et al. 2017). By recognizing the geomorphological terrains of sand dune source areas and determinin their contribution to sediment production, the control of sediment production can be planned. Sourcing methods were developed in the late 1980s and 1990s based on various quantitative approaches (Walling 2005) including the use of quantitative hybrid models (Collins and Walling 200). 
The fingerprinting technique is one such sourcing method and it has two main aspects: 1) determining the best tracers in both sediments and potential source units; 2) solving multiple fingerprinting equations for determining sediment contributions from each geomorphologic mapping unit (GMU) (Adabi 2004). Most investigations of aeolian sediment sources have used mixing models that have included isotopes and geochemical properties (Collins et al. 2010; Honda et al. 2004; Saye and Kenneth 2006; Wang et al. 2012). But here only major elements are used as they are easier to obtain and, it will be shown, produce reliable results.

In recent decades Lake Urmia has been affected by human activities such as dam construction in its upland catchment (AghaKouchak et al. 2015), water level loss by climatic change (such as decreased rainfall, increased evaporation and wind speed), and land use changes have led to shrinkage of the lake. Together with vegetation loss but dune enchroachment, new geomorphologic terrains have been created on the exposed lake floor. The creation of sand dunes from the newly exposed terrain (Boroughani et al. 2020), including salty particles, has led to undesirable conditions for agriculture, human health, with the creation of threats to socio-economic conditions and the environment, affecting two provinces in northwestern Iran (Katebi et al. 2018).

60

The main aim of this study is to link the newly formed sand dunes to their sediment sources that have been exposed by drying of the Urmia Lake, through multiple fingerprinting models as well as assessment of uncertainty through statistical analysis. This approach involved the following steps: 1) measurement of the chemical composition of sediments and corresponding GMU by XRF and calculation of the chemical index of alteration (CIA) (Motha et al. 2003; Honda et al. 2004); 2) Calculation of the contribution of each GMU to the dominant sand fraction though multiple fingerprinting equations and a Bayesian approach; and 3) estimation of the uncertainty related to each contribution using GLUE and Bayesian approaches.

\section{Materials and Methods}

69

\subsection{Study area}

70

71

The study area is located on the western margin of Urmia Lake in the northwest of Iran. The lake and newly exposed dry bed covers an area of approximately $10 \mathrm{~km}^{2}$, between $37^{\circ} 45^{\prime}$ to $37^{\circ} 57^{\prime} \mathrm{N}$ latitude and $45^{\circ} 01^{\prime}$ to $45^{\circ} 57^{\prime}$ E longitude (Figure.1). A study of the wind regime at Urmia Station (Figure .1) showed that Southwest winds (15.4\%) prevail, and the sand drift potential is 63 VU (Nazari Samani et al. 2018) which causes sand to move to the Northeast (Figure.2). The major sediments of the study area are of the Quaternary period. When Urmia Lake began to dry up in 2003 (Figure.3), new geomorphologic units appeared (Figure. 4). On this newly exposed surface, vegetation is sparse and scattered and mainly consists of halophyte and hydro-halophyte species such as Nitrartia schoberi and Haloxylon spp. Tamarix spp. have been established in the riparian zones along the ephemeral wadis that feed the lake. 
83

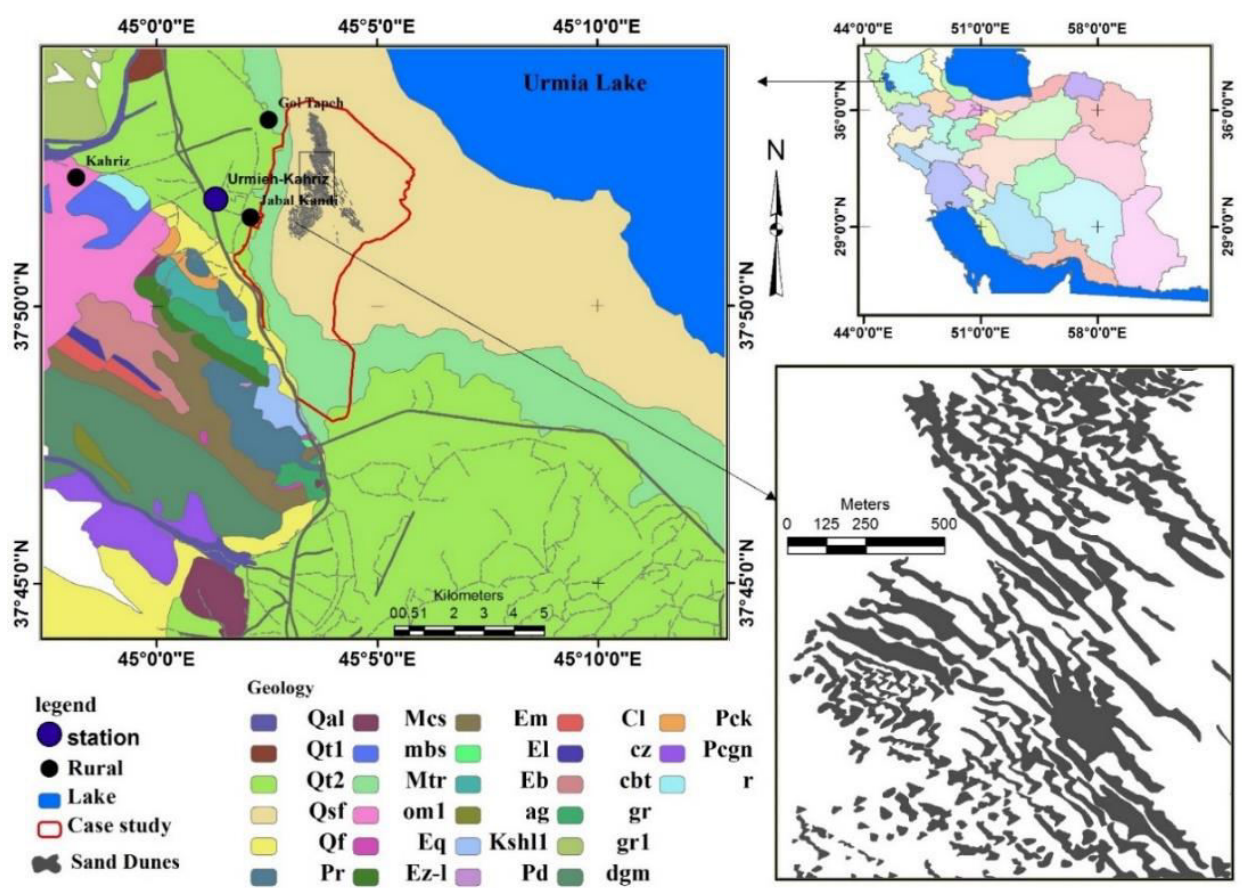

Figure 1. Location of the study area in the North West of Iran
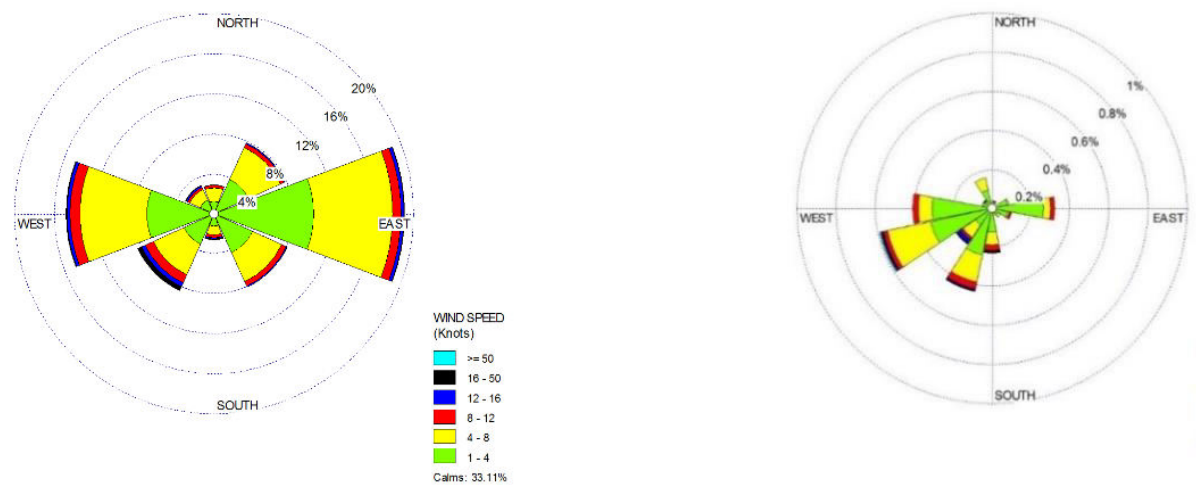

(a)

(b)

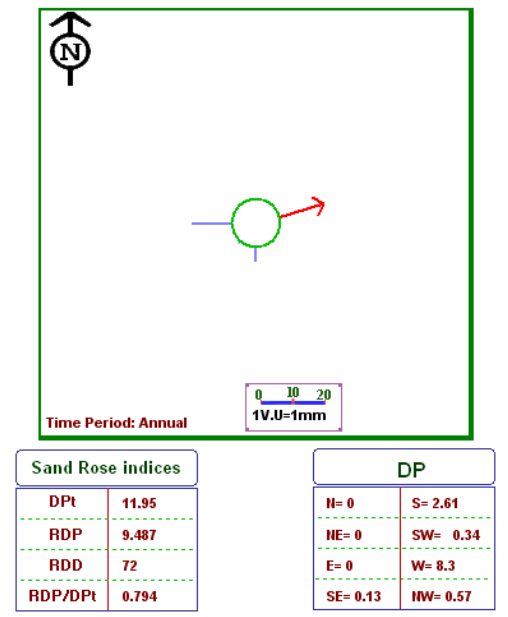

(c)

Figure 2. Annual wind rose graph: (a) storm rose graph (b) and sand rose graphat Urmia Station (c) 


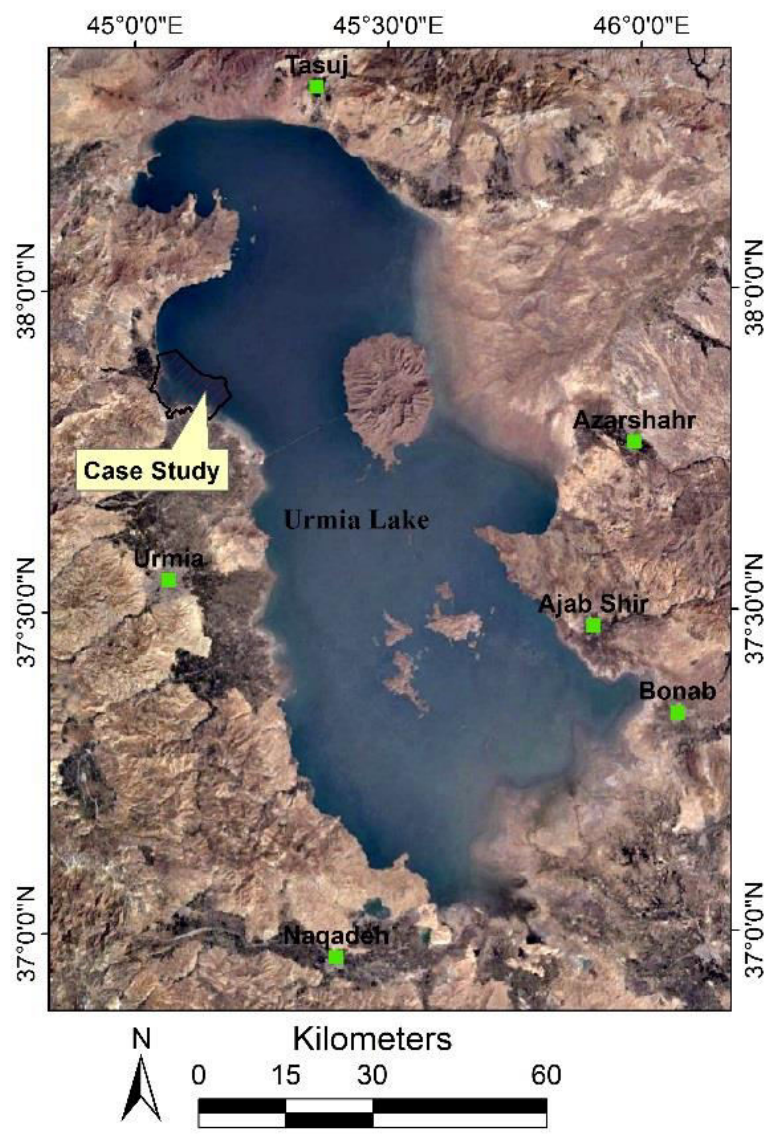

1996
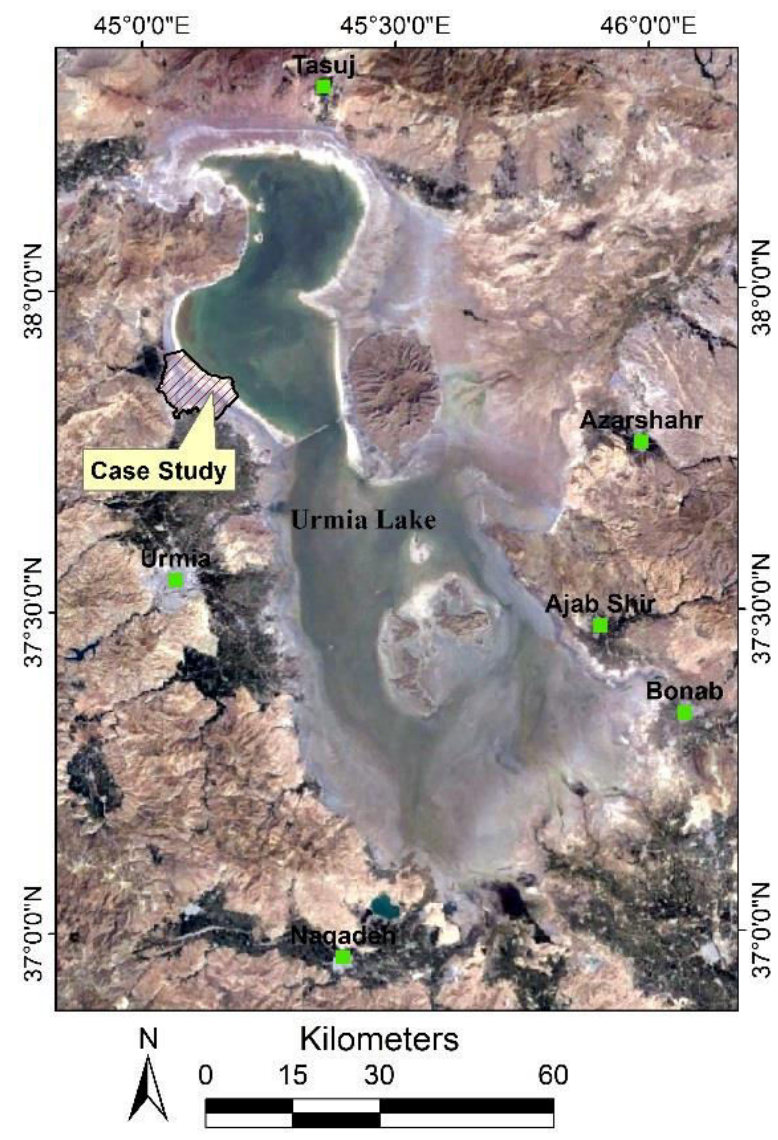

2016

Figure 3. Shrinkage of the Urmia Lake over the past decades and the location of the newly generated sand dunes
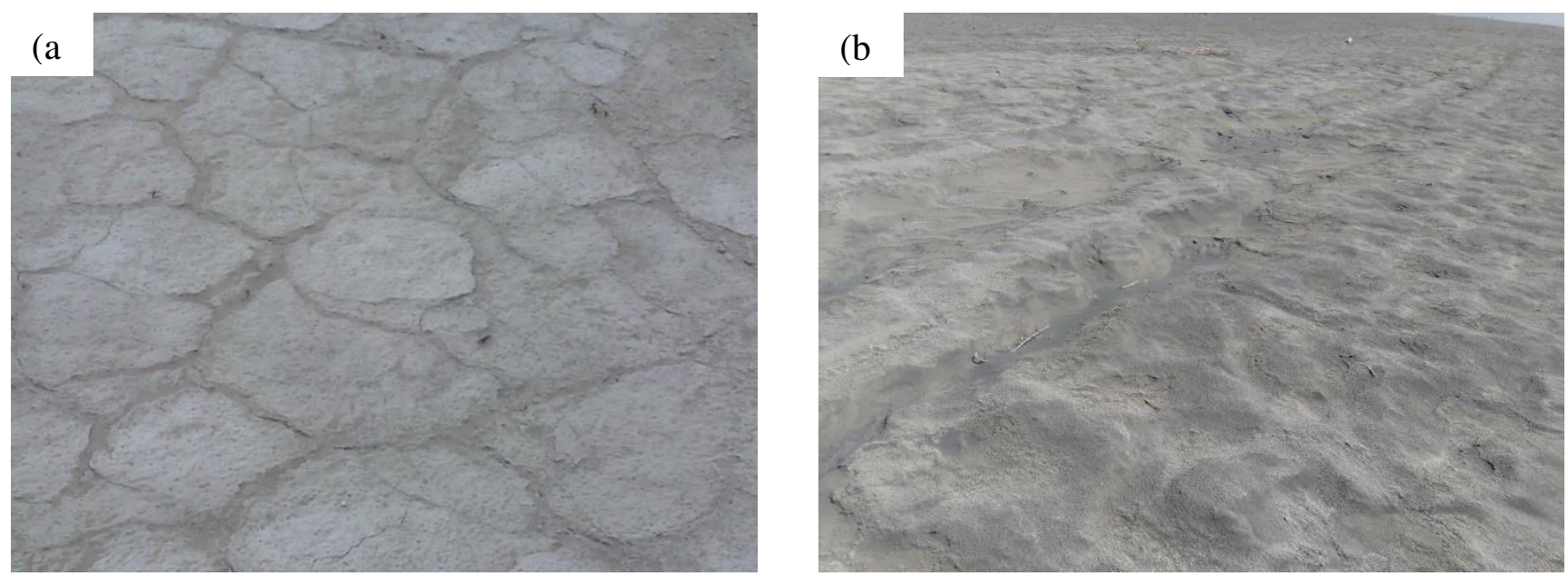

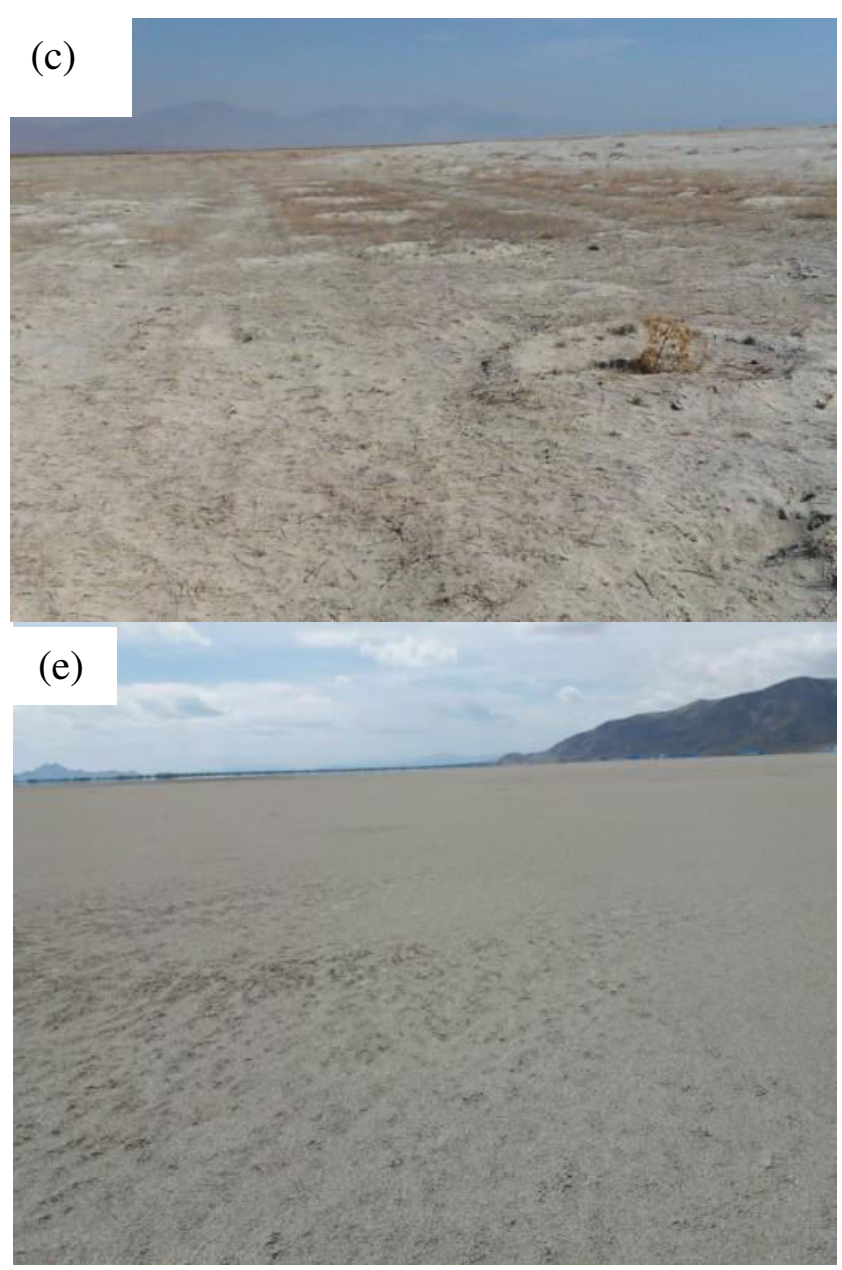

(a): salty polygon

(b): Salty and puffy lands

(c ): Clay, salty areas, puffy and flaky lands

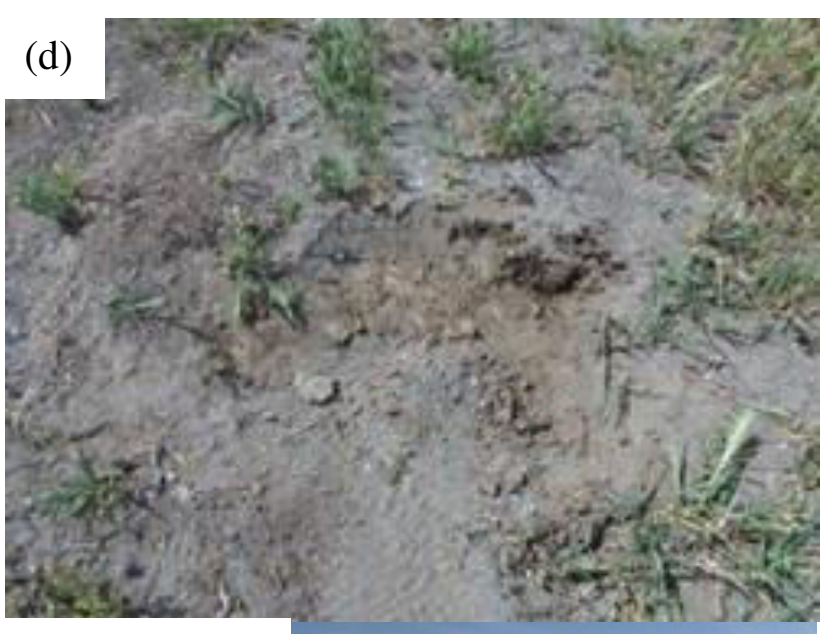

Sand dune

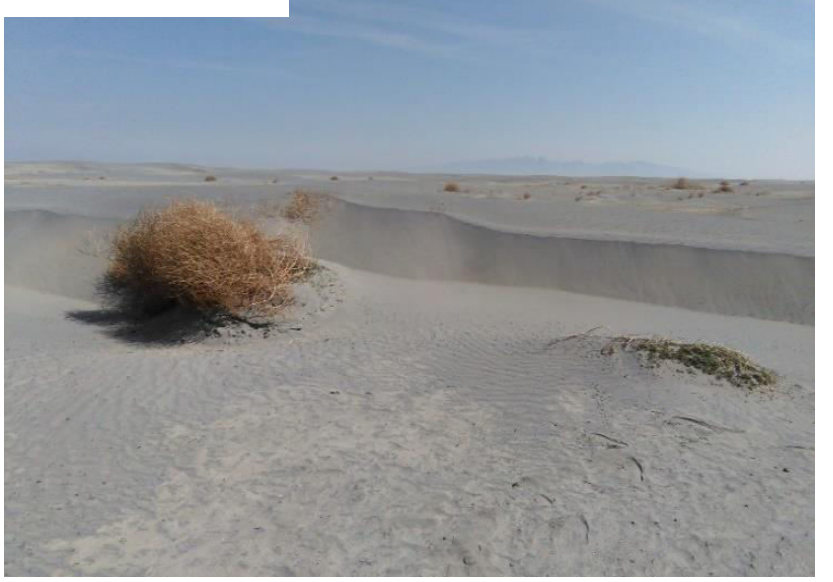

(d): Terminus of the fine sandy alluvial fan

(e): clay, salty and abandoned lands

Sand dune

Figure 4. The major geomorphic units (GMU) of Urmia Lake. These are a sample of different GMUs used to separate the source areas

\subsection{Sample collection and geochemical analysis}

The geomorphological mapping units (GMU) were identified from interpretations of images, slope condition and lithological information as well as field studies (Figure.5). Based on the terrain map, 23 samples were collected, including 15 samples from potential geomorphic sources, and eight samples from sand dunes (windward and leeward sides of dunes). A random sampling strategy was used to collect samples from the upper 0-5 cm surface soil of GMU and sand dunes. During the field sampling we tried to keep 500 meters' distance between two points along a sampling transect line.

All of the samples were sieved, and particle size distributions determined by drawing granulometric curves. The particle size fraction with $>50 \%$ frequency is $125-500 \mu \mathrm{m}$, therefore this fraction was selected for chemical analysis. The samples were analyzed by XRF to provide estimates of the major elements: $\mathrm{Cl}, \mathrm{S}, \mathrm{As}, \mathrm{Ba}, \mathrm{Ce}, \mathrm{Co}, \mathrm{Cr}, \mathrm{Cu}, \mathrm{Nb}, \mathrm{Ni}, \mathrm{Pb}, \mathrm{Rb}, \mathrm{Sr}, \mathrm{V}, \mathrm{Y}, \mathrm{Zr}, \mathrm{Zn}, \mathrm{Mo}$. And the following compounds of Earth's crust were also determined: $\mathrm{SiO} 2, \mathrm{Al} 2 \mathrm{O} 3, \mathrm{Fe} 2 \mathrm{O} 3, \mathrm{CaO}, \mathrm{Na} 2 \mathrm{O}, \mathrm{MgO}, \mathrm{K} 2 \mathrm{O}$, $\mathrm{TiO} 2, \mathrm{MnO}, \mathrm{P} 2 \mathrm{O} 5$, as well as LOI.

The CIA (McLennan 1993) is an indicator of the degree of weathering of the aluminum-silicate minerals (Eq. 1) (Honda et al. 2004): 
$106 \mathrm{CIA}=[\mathrm{Al} 2 \mathrm{O} 3 /(\mathrm{Al} 2 \mathrm{O} 3+\mathrm{CaO}+\mathrm{Na} 2 \mathrm{O}+\mathrm{K} 2 \mathrm{O})] \times 100$

107 The CIA value indicates the degree to which minerals have been converted to clay, and in the present 108 case range from 45 to 55 indicating minimal weathering. A value of 100 indicates complete weathering 109 (Motha et al. 2003).

110 The salinity levels of the sands were determined and classified according to the scheme of (Besler 111 2003). The types of sand dunes have been determined based on their salt content, allowing the 112 distinction between sand dunes (not saline: $<102 \mathrm{mS} / \mathrm{cm}$ ), mega dune sands (saline: $>102 \mathrm{mS} / \mathrm{cm}$ ), 113 aeolian sediments subjected to surface-water infiltration and evaporation during long timespans 114 (strongly saline: $>103 \mathrm{mS} / \mathrm{cm}$ ), and littoral sands influenced by sea salt water (extremely saline: $115>104 \mathrm{~ms} / \mathrm{cm})($ Besler 2003). 


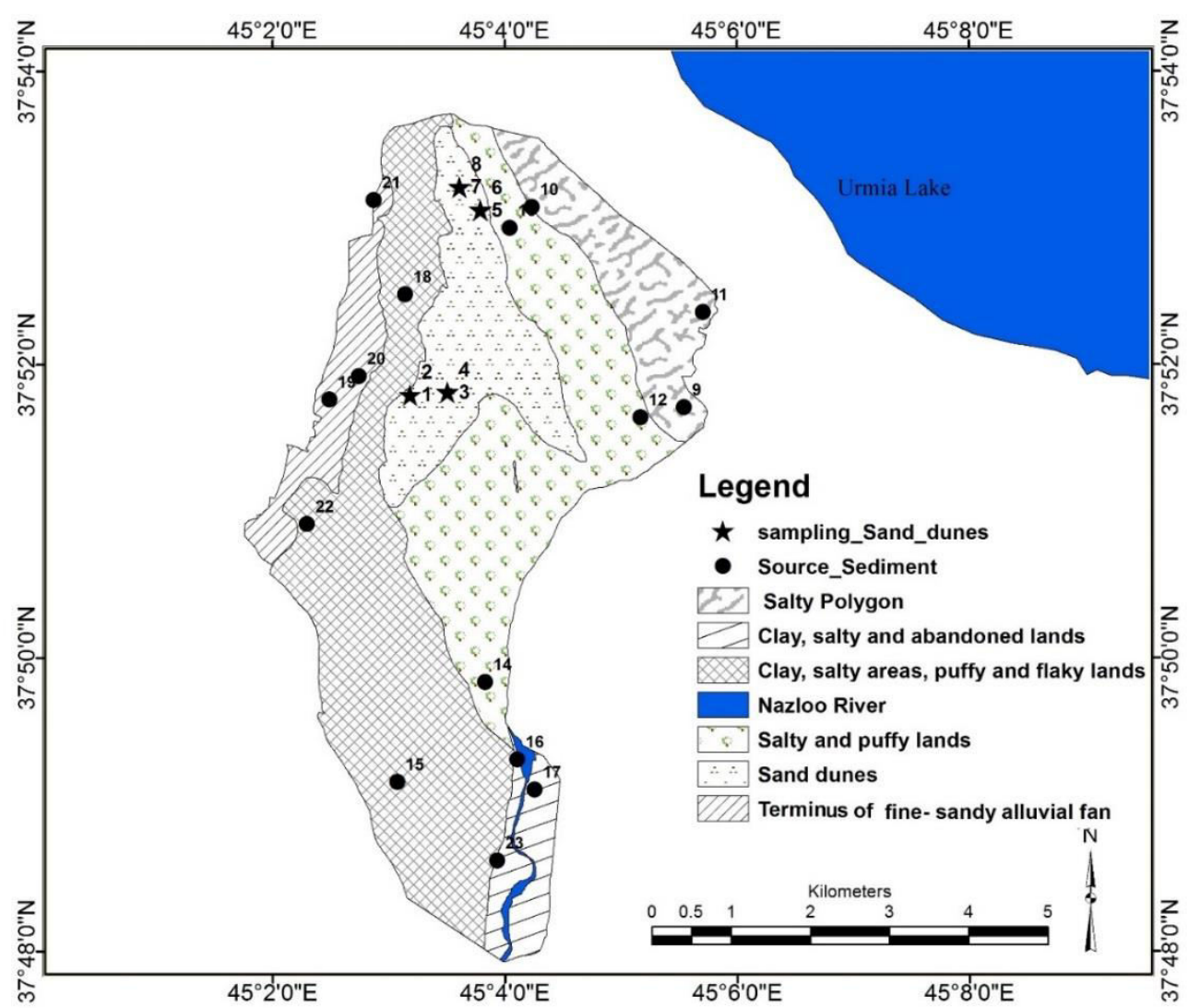

Figure 5. Geomorphological Mapping Units and the locations of sampling points

\subsection{Optimum tracing composite and sand provenance}

Multiple tracers were selected based on a pre-sourcing study (Boroughani et al. 2020) and geochemical variation. The fraction of $125-500 \mu \mathrm{m}$ was used for analysis because it is the dominant size fraction. All elemental data were used as a starter list of tracers and through simple and multivariate data analysis the tracers that can distinguish different sources were identified. Small differences among the source groups were not used for the final tracer list. A principal component analysis (PCA) was applied to group the tracer signatures according to variability and statistical distance from each other. Finally, a stepwise multivariate discriminant function analysis (DFA) was applied to the data to extract a suitable set of properties for predicting source membership. Tests for outliers and normality were done using box plots and the Kolmogorov-Smirnov test, respectively.

\subsection{Relative source contribution estimation using a Bayesian mixing model}

Suppose $\mathrm{Y}$ is an $\mathrm{n} \times \mathrm{k}$ matrix representing $\mathrm{n}$ measured tracers in $\mathrm{k}$ sediment samples and $\mathrm{S}$ is an $n \times m$ matrix of $n$ measured tracers in $m$ sources (each column represents $n$ measured tracers in each source). Let $\mathrm{B}$ be an $\mathrm{m} \times \mathrm{k}$ matrix of $\mathrm{m}$ fractional source contributions to $\mathrm{k}$ sediment samples. Note that all elements in this vector are non-negative and sum to unity. The mixing problem can be expressed using a multivariate linear model (Eq. 2):

$Y=S B+E$

where $\mathrm{E}$ is an $\mathrm{n} \times \mathrm{k}$ error matrix. 
When the number of tracers is equal to or more than the number of sources, the system of linear equations is mathematically over determined and there are infinite solutions. To estimate the source contribution matrix (B), frequentist statisticians employ an optimizing algorithm to minimize objective functions such as the root mean square of relative errors (Motha et al. 2003). Problems such as a limited number of samples used to represent tracer concentrations in sources, the optimization algorithm used to minimize an objective function, the number of selected tracers, the use of a single value of tracers for each source in the mixing model, and analytical errors of the tracers combine to produce uncertainty in estimated source contributions (Franks and Rowan 2000; Small et al. 2002; Collins et al. 2010; Walling 2013). Knowledge of uncertainty ranges enables a realistic assessment of sediment fingerprinting results.

To quantify uncertainty associated with variability of the fingerprint properties in the sources and sediment, many researchers couple Monte Carlo simulation with a mixing model (Franks and Rowan 2000; Martínez et al. 2010; Collins et al. 2010). The Monte Carlo approach ignores correlation between tracers in modeling and it has insufficient flexibility to take account of all sources of uncertainty (Cooper et al. 2015). Recently different Bayesian mixing models have been developed to deal with the drawbacks of the Monte Carlo technique and to estimate uncertainty in sediment fingerprinting (Douglas et al.2009, Stewart et al. 2015; Mabit et al.2018).

\subsection{Uncertainty estimation base on a Bayesian mixing model}

In this study we used a hierarchical Bayesian end-member model (BEMMA) to estimate the uncertainty in sediment fingerprinting. This model was originally developed by (Yu et al. 2018) to unmix sediment sources and determine their contribution to sinks from sediment grain-size data.

Based on Bayes' theorem, the probability of event A given event B is proportional to the probability of event B given event A multiplied by its prior probability (Eq. 3):

$\mathrm{p}(\mathrm{A} \mid \mathrm{B}) \propto \mathrm{P}(\mathrm{B} \mid \mathrm{A}) \mathrm{p}(\mathrm{A})$

The Bayesian theorem states that the initial belief (i.e., prior knowledge) about parameter A can be updated by observational data so as to find the posterior distribution of parameter A.

Within the Bayesian framework, we assume that the likelihood follows the multivariate normal distribution with covariance matrix $\sum$ (Eq. 4):

$\mathrm{l}(\mathrm{Y} \mid \mathrm{S}, \mathrm{C}, \Sigma)=(2 \pi)^{-\frac{\mathrm{kn}}{2}}\left|\Sigma^{-1}\right|^{\frac{\mathrm{k}}{2}} \prod_{\mathrm{i}=1}^{\mathrm{k}} \exp \left[-\frac{1}{2}\left(\mathrm{y}_{\mathrm{i}}-\mathrm{Sb}_{\mathrm{i}}\right)^{\mathrm{T}} \Sigma^{-1}\left(\mathrm{y}_{\mathrm{i}}-\mathrm{Sb}_{\mathrm{i}}\right)\right]=$

$(2 \pi)^{-\frac{k n}{2}}\left|\Sigma^{-1}\right|^{\frac{k}{2}} \exp \left\{-\frac{1}{2} \operatorname{tr}\left[(Y-S C)(Y-S C)^{T} \Sigma^{-1}\right]\right\}$

Where $\mathrm{T}$ denotes the transpose of a matrix or a vector, $\mid \mathrm{|}$ is the determinant and $\operatorname{tr}($. denotes the tracer matrix.

An important component of Bayesian modeling is to define a suitable prior distribution for parameters and hyper-parameters. Depending on prior knowledge and the complexity of a 
model, one can select informative and non-informative parameters or some parameters and hyper-parameters that are directly estimated using measured data (Carlin 1996).

For source fractional contributions we adopted the non-informative Dirichlet distribution as a prior to ensure that fractional source contributions are positive and sum to one.

$y_{i} \sim \operatorname{Dirichlet}\left(\lambda_{i}\right)$

where $y_{i}$ is an $\mathrm{m}$ dimensional vector of the fractional source contribution to sediment sample i and $\lambda_{i}$ is the Dirichlet distribution parameter.

For the inverse covariance matrix $\left(\Sigma^{-1}\right)$, the Wishart distribution $(\psi, v)$ was selected as the prior distribution, where the hyper-parameter $v>n-1$ is the degrees of freedom and the hyper-parameter $\psi$ is a $\mathrm{n} \times \mathrm{n}$ positive definite scale matrix. In this study $v$ was set to $\mathrm{n}$ and for $\psi$ we assume the Wishart distribution $(\Omega, p)$, due to lack of prior knowledge, and $\mathrm{P}$ was set to n and $\Omega$ was set to $P \mathrm{I}_{n}$.

Due to the complexity of the posterior distribution, an analytical method cannot be used to infer the unknown parameters; therefore, we used the reversible-jump Markov chain Monte Carlo algorithm in conjunction with the Gibbs samplers to sample the posterior distributions so as to generate random numbers that mimic the posterior distribution of the parameters.

\subsection{Uncertainty estimation base on the GLUE method}

The Generalized Likelihood Uncertainty Estimation (GLUE) method is based on the equifinality concept and was originally developed by (Beven 2006) to estimate uncertainties in hydrological models. This method rejects a single optimum parameter set and states that there are several and different parameter sets that provide a good fit to observed data (Blasone et al. 2008).

Because it is a simple concept, is relatively easy to implement and is flexible, this method is widely used in many areas of environmental modeling (Vrugt et al. 2009; Blasone et al. 2008). In the GLUE method all sources of uncertainty, such as input and output uncertainties, parameter uncertainty and model structure uncertainty are included in the total parameter uncertainty (Shen et al. 2012). This method does not make any assumptions about input and error distributions (Dotto et al. 2012). To conduct the GLUE method to estimate uncertainty we used the following steps.

Select a prior distribution to sample feasible parameter sets. Note that in the mixing model the source contributions are the parameters. Due to lake of prior knowledge about parameter sets, a uniform distribution was selected as the prior distribution to sample parameter sets.

Select a likelihood function and threshold value to split all parameter sets into behavioral and non-behavioral parameter sets. In this study the Nash-Sutcliffe coefficient (Nse) was selected as the likelihood function (Eq. 6).

Nse $=1-\frac{\sum\left(y_{o b s}-y_{\text {sim }}\right)}{\sum\left(y_{o b s}-\bar{y}_{o b s}\right)}$

where; $\bar{y}_{\text {obs }}$ represents mean values of observed tracer concentrations in the sediment; $y_{\text {sim }}$ are the estimated values of tracer concentrations in sediment samples; and $y_{o b s}$ are observed tracer concentrations in the sediment. 
The Nse values range from $-\infty$ to 1 . The value of Nse equaling 1 indicates perfect correspondence between observed and simulated values and minus values indicate poor performance of the model.

Latin hypercube sampling was employed to generate random parameter sets from the prior distribution. Then the mixing model was run with sampled parameter sets and Nse was calculated for each parameter set. Here parameter sets were sampled 200,000 times.

Dividing parameter sets into behavioural and nonbehavioural with respect to selected thresholds and calculated likelihood values for each parameter set. For the next step nonbehevioural parameter sets were discarded.

For all parameter sets, likelihood values were rescaled to cumulatively sum to 1 . For each source, fractional contributions were sorted in ascending order and, using assigned weights, the cumulative distribution was calculated, and finally different quintiles were estimated.

\section{Results}

The CIA index, the enrichment ratio and the amount of salinity are shown in (Table 1), showing that weathering is low. The main reason for the low weathering status is the very dry climate (and youth of the exposed source materials remaining from drawdown of the lake) that has allowed the preservation of unstable minerals. Maximum electrical conductivity was found in the Salty Polygon GMU $\left(9333 \mu \mathrm{S} / \mathrm{cm},>10^{3}\right)$, and sand dunes have values between $270 \mu \mathrm{S} / \mathrm{cm}$ and $950 \mu \mathrm{S} / \mathrm{cm}$ in sand dune 7 and sand dune 4 , respectively. Also, the results of normalization of elements in all terrains are shown in Figure 6-a-b.

Table 1. The CIA index, enrichment ratio and Salinity

\begin{tabular}{ccccccccc}
\hline GMU & $\mathrm{SiO}_{2}$ & $\mathrm{Al}_{2} \mathrm{O}_{3}$ & $\mathrm{Fe}_{2} \mathrm{O}_{3}$ & $\mathrm{Cao}$ & $\mathrm{Na}_{2} \mathbf{O}$ & $\mathrm{K}_{2} \mathbf{O}$ & $\begin{array}{c}\mathrm{CIA} \\
(\%)\end{array}$ & $\begin{array}{c}\text { salinity } \\
\mu \mathrm{S} / \mathbf{c m}\end{array}$ \\
\hline Sand dune1(Stoss) & 12.76 & 1.89 & 1.32 & 41.39 & 0.38 & 0.81 & 4.3 & 420 \\
Sand dune2 (Lee ward) & 13.29 & 2.04 & 1.42 & 40.69 & 0.41 & 0.87 & 4.63 & 880 \\
$\quad$ Sand dune3 (Stoss) & 13.65 & 2.18 & 1.47 & 40.37 & 0.42 & 0.86 & 4.96 & 570 \\
Sand dune4 (Lee ward) & 10.73 & 1.55 & 1.35 & 42.65 & 0.46 & 0.63 & 3.42 & 950 \\
$\quad$ Sand dune5(Stoss) & 9.98 & 1.32 & 1.09 & 43.19 & 0.31 & 0.47 & 2.91 & 260 \\
Sand dune6 (Lee ward) & 9.53 & 1.50 & 1.10 & 44.71 & 0.54 & 0.47 & 3.18 & 350 \\
$\quad$ Sand dune7 (Stoss) & 9.89 & 1.45 & 1.13 & 43.46 & 0.35 & 0.57 & 3.16 & 270 \\
Sand dune8 (Lee ward) & 9.20 & 1.66 & 1.29 & 42.45 & 0.26 & 0.62 & 3.68 & 300 \\
$\quad$ Salty polygon (A) & 0.86 & 0.7 & 1.4 & 23.18 & 2.37 & 0.95 & 10.1 & 9333 \\
Salty and puffy lands (B) & 0.55 & 0.4 & 0.95 & 26.44 & 2.85 & 0.63 & 4.8 & 7800 \\
Clay, salty areas, puffy and & 1.84 & 1.7 & 2.55 & 11.86 & 0.76 & 2.20 & 31.2 & 1356 \\
$\quad$ flaky lands (C) & & & & & & & & \\
Terminus of the fine sandy & 1.19 & 0.9 & 2.21 & 13.41 & 0.32 & 1.19 & 18.0 & 397 \\
$\quad$ alluvial fan (D) & & & & & & & & \\
Clay, salty and abandoned & 0.93 & 1.03 & 2.06 & 22.64 & 1.28 & 1.29 & 18.9 & 2503 \\
$\quad$ lands (E) & & & & & & & & \\
\hline
\end{tabular}

In the study area, most of the rare elements are $\mathrm{As}, \mathrm{Sr}, \mathrm{Pb}, \mathrm{Mo}$ and $\mathrm{Cl}$. The high presence of these elements is because of the acidic environment caused by oxidation of igneous and metamorphic rocks in the catchment. Also, a large amount of $\mathrm{Cl}$ is due to the presence of salty polygon land caused by the drying up of Urmia Lake (Figure 6). The pre-statistical 
analysis for testing the normality and outlier cases and variables was done by the Kolmogorov-Smirnov test and box plot diagram respectively (Table 2). The descriptive statistics show that the maximum element is $\mathrm{Cl}$ (53791) and the minimum is $\mathrm{MnO}(0.02)$, and the skewness index for all tracers (except, $\mathrm{LOI}, \mathrm{CaO}$, Mo and $\mathrm{Zr}$ ) is positive.
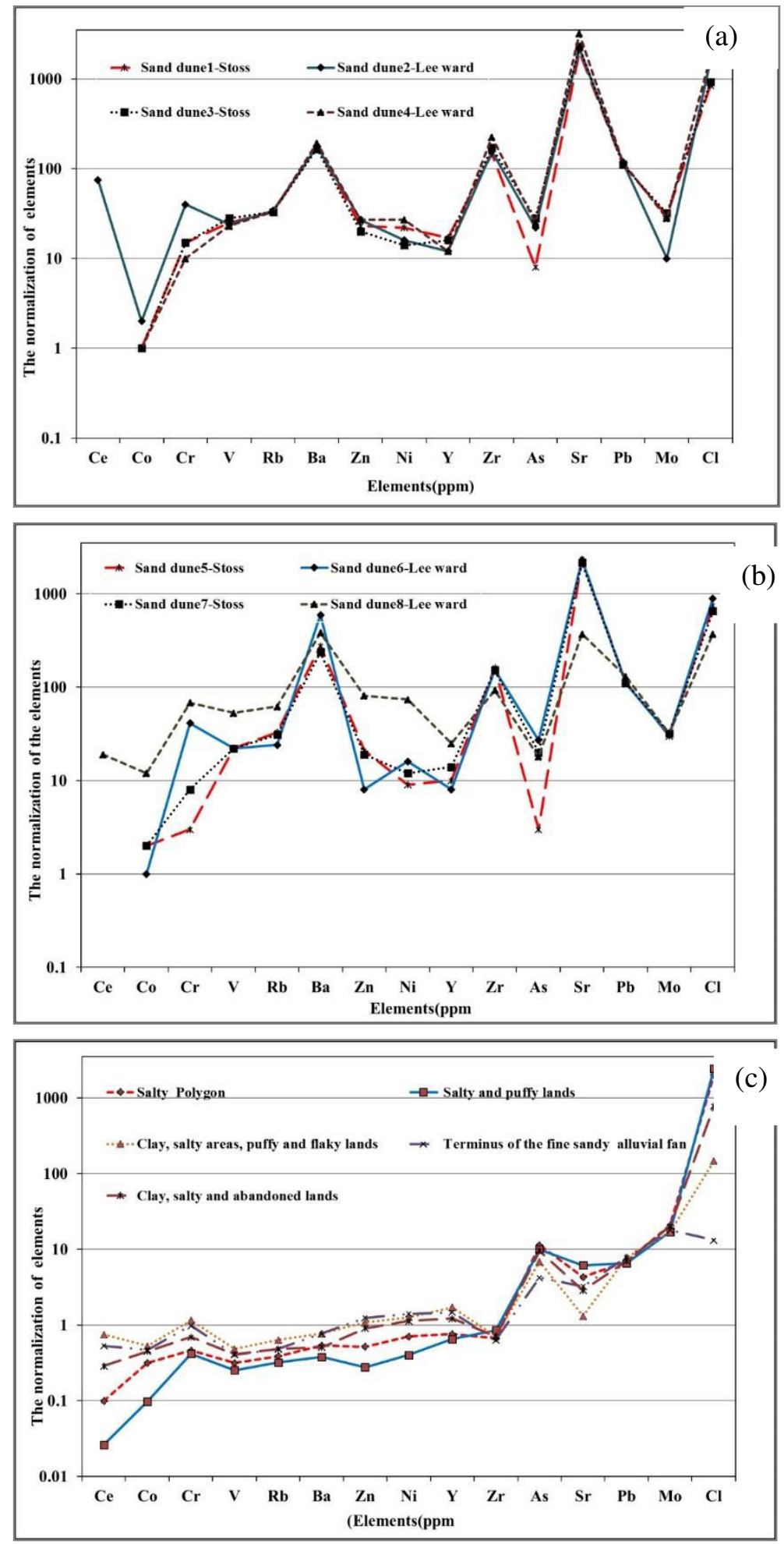

Figure 6. The normalization of elements in the sand dunes (a)(b)and source sediment (c)

Table 2. Kolmogorov-Smirnov test and descriptive statistics of tracers 


\begin{tabular}{cccccccc}
\hline \multirow{2}{*}{ Tracers } & \multicolumn{3}{c}{ Kolmogorov-Smirnov test } & \multicolumn{5}{c}{ Descriptive statistics } \\
\cline { 2 - 7 } & K-S & Sig & Max & Min & Mean & Stdev & Skew \\
\hline $\mathrm{Cl}$ & 0.6 & 0.8 & 53791 & 128 & 9919.5 & 16245.7 & 1.53 \\
$\mathrm{~S}$ & 0.5 & 1 & 5489 & 54 & 1906.3 & 1307.9 & 1.35 \\
$\mathrm{As}$ & 0.6 & 0.8 & 28 & 30 & 17.05 & 7.57 & 0.27 \\
$\mathrm{Ba}$ & 1.1 & 0.2 & 593 & 144 & 313.45 & 139.9 & 0.75 \\
$\mathrm{Ce}$ & 1 & 0.3 & 75 & 5 & 44.44 & 24.31 & 0.26 \\
$\mathrm{Co}$ & 1 & 0.3 & 19 & 1 & 4.82 & 4.96 & 1.48 \\
$\mathrm{Cr}$ & 1 & 0.3 & 122 & 1 & 46.78 & 39.47 & 0.62 \\
$\mathrm{Ni}$ & 1 & 0.3 & 104 & 9 & 35.59 & 27.9 & 1.08 \\
$\mathrm{~Pb}$ & 0.6 & 0.8 & 142 & 105 & 11.52 & 11.48 & 0.62 \\
$\mathrm{Rb}$ & 1 & 0.3 & 102 & 21 & 44.6 & 20.62 & 1.37 \\
$\mathrm{Sr}$ & 1 & 0.3 & 3184 & 191 & 1647.6 & 930.88 & 0.47 \\
$\mathrm{~V}$ & 1 & 0.3 & 78 & 20 & 34.26 & 15.92 & 1.34 \\
$\mathrm{Y}$ & 0.6 & 0.9 & 57 & 8 & 30.96 & 13.39 & 1.29 \\
$\mathrm{Zr}$ & 0.8 & 0.5 & 226 & 31 & 147.2 & 40.5 & -0.59 \\
$\mathrm{Zn}$ & 1.1 & 0.2 & 138 & 8 & 44.35 & 37 & 1.18 \\
$\mathrm{Mo}_{\mathrm{n}}$ & 0.4 & 1 & 33 & 10 & 27.52 & 7.5 & -1.5 \\
$\mathrm{SiO}_{2}$ & 1 & 0.3 & 58.02 & 0.8 & 19.24 & 13.96 & 1.3 \\
$\mathrm{Al} \mathrm{O}_{3}$ & 1 & 0.3 & 12.08 & 0.53 & 3.71 & 3.33 & 1.39 \\
$\mathrm{Fe} 2 \mathrm{O}_{3}$ & 1 & 0.3 & 6.52 & 0.7 & 2.22 & 1.52 & 1.4 \\
$\mathrm{CaO}$ & 1 & 0.3 & 53.15 & 8.9 & 32.5 & 12.5 & -0.54 \\
$\mathrm{Na}_{2} \mathrm{O}$ & 1 & 0.3 & 5.39 & 0.2 & 1.4 & 1.6 & 1.39 \\
$\mathrm{MgO}$ & 1 & 0.3 & 12.72 & 0.7 & 3.1 & 2.6 & 2.35 \\
$\mathrm{~K}_{2} \mathrm{O}$ & 1 & 0.3 & 3.04 & 0.3 & 1.1 & 0.8 & 1.14 \\
$\mathrm{TiO}_{2}$ & 1 & 0.3 & 0.7 & 0.05 & 0.22 & 0.19 & 1.17 \\
$\mathrm{P}_{2} \mathrm{O}_{5}$ & 1.5 & 0 & 0.99 & 0.06 & 0.17 & 0.2 & 3.38 \\
$\mathrm{LOI}$ & 1 & 0.3 & 42.36 & 8.7 & 33.94 & 8.4 & -1.6 \\
\hline & & & & & & &
\end{tabular}

Based on the PCA and DFA the optimal tracers were determined, namely Mo and $\mathrm{Na}_{2} \mathrm{O}$ and $\mathrm{S}$ and have been used for fingerprinting. According to the mixing model the relative contributions of each GMU are as follows: 1) salty polygon lands (A, 23.5\%); 2)Salty and puffy lands (B, 44.2\%); 3), clay, salty areas, puffy and flaky lands (C, 7.01\%); 4) terminus of the fine sandy alluvial fan (D,13.2\%); and 5) clay, salty and abandoned lands (E,12.1\%) (Table 3).

Table 3. The relative contribution of sand dune sources using GLUE and Bayesian models

\begin{tabular}{ccccc}
\hline Sources & & area $\%$ & GLUE\% & Bayesian $\%$ \\
\hline salty polygon & A & 12.5 & 30.9 & 23.5 \\
Salty and puffy lands & $\mathrm{B}$ & 32.1 & 45.8 & 44.2 \\
Clay, salty areas, puffy and flaky lands & $\mathrm{C}$ & 42.0 & 3.8 & 7.01 \\
Terminus of the fine sandy alluvial fan & $\mathrm{D}$ & 7.8 & 10.8 & 13.2 \\
Clay, salty and abandoned lands & $\mathrm{E}$ & 5.5 & 8.8 & 12.1 \\
Total & & 100 & 100 & 100 \\
\hline
\end{tabular}

Also Figure. 7 depicts the relative contribution to the sand dunes of sediments from the various sources with their variability according to the GLUE and Bayesian approaches. 
Source B and then source A have the highest contribution to the sand dunes compared to the other sources. Sand dune samples 1 to 4 were located in the southern sand dunes, 5 to 8 located in the northern part of the region, but the sources and their proportions however remain the same for both sets of dunes.
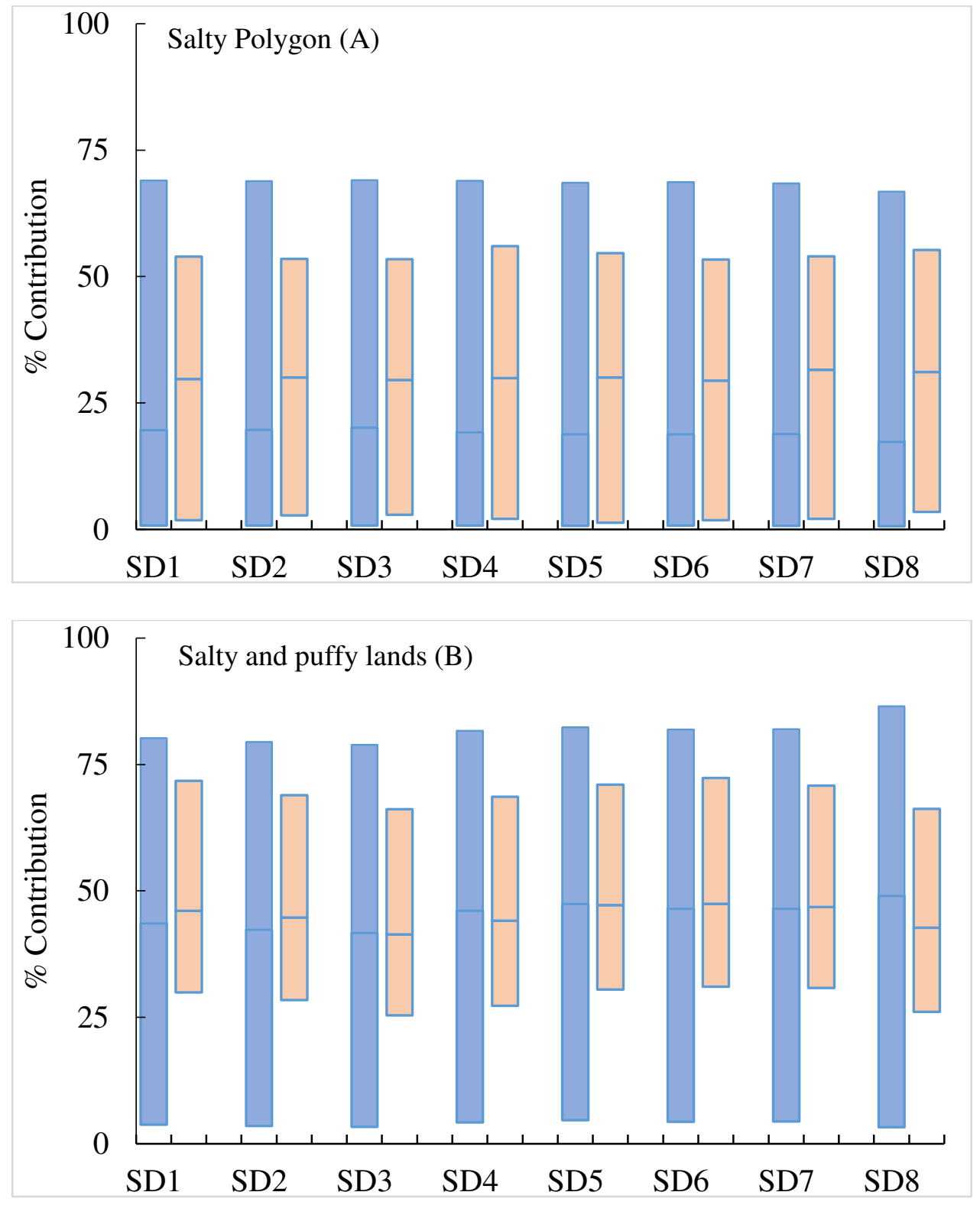

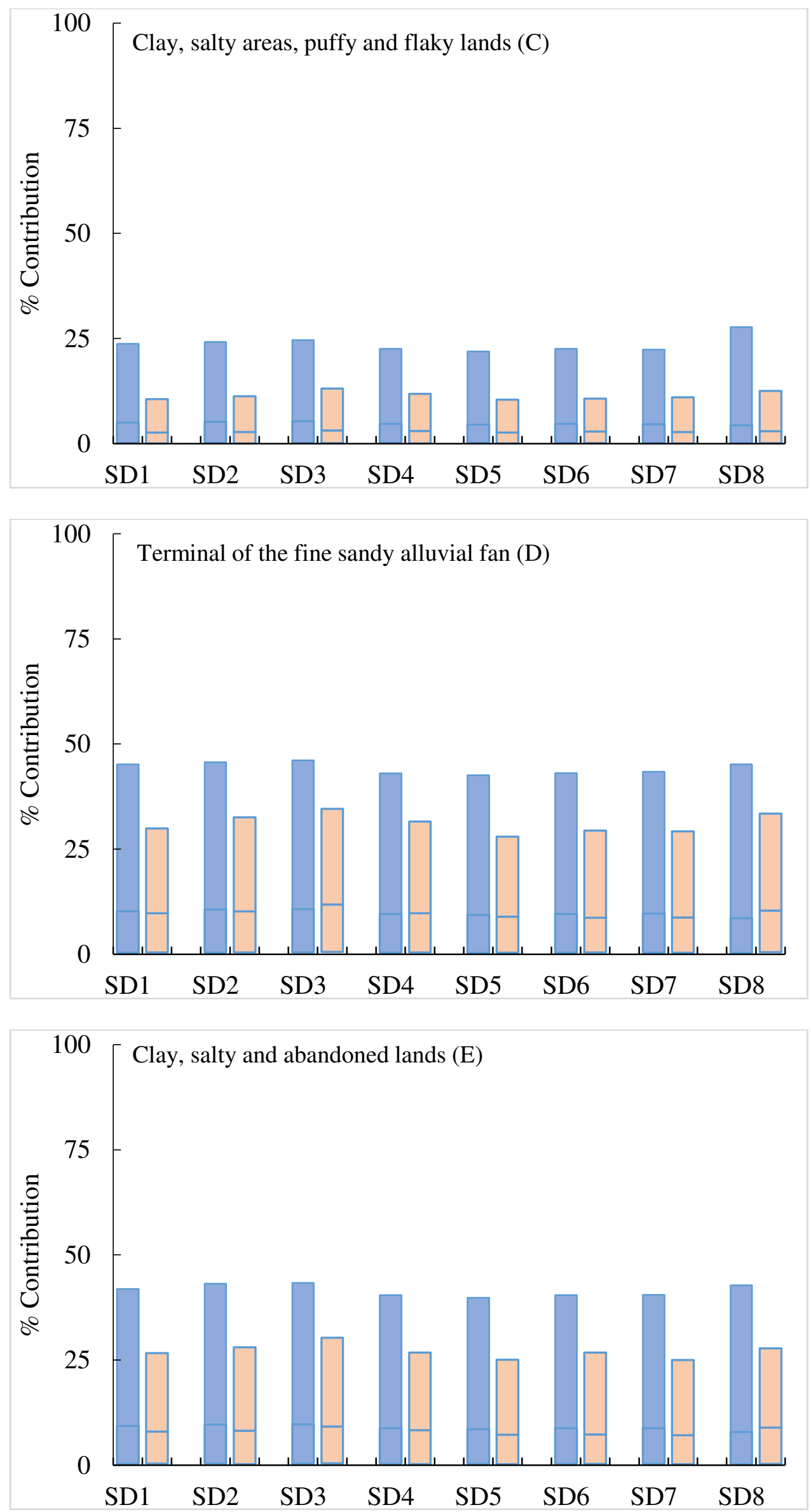
Figure 7. Relative contribution to the supply of sand to the dunes from the different sources: GLUE approach (Blue) and Bayesian approach (gray).

For a closer examination of the estimated source contributions and associated uncertainties, three quintiles of source contributions $(0.025 \%, 0.5 \%$ and $0.975 \%$ quintiles) have been estimated using the GLUE and Bayesian methods for each sediment sample (Table 4).

Table 4. The uncertainties of sediment source terrains using the Bayesian and GLUE approaches.

\begin{tabular}{|c|c|c|c|c|c|c|c|c|c|c|c|}
\hline \multirow{3}{*}{$\begin{array}{r}\text { Sand } \\
\text { dunes }\end{array}$} & \multirow{3}{*}{$\begin{array}{c}\text { Uncertaint } \\
\mathbf{y} \\
\text { Estimatio } \\
\mathbf{n} \\
\text { (Average } \\
\% \text { ) }\end{array}$} & \multicolumn{5}{|c|}{ Bayesian Model } & \multicolumn{5}{|c|}{ GLUE Model } \\
\hline & & \multicolumn{5}{|c|}{ Sources } & \multicolumn{5}{|c|}{ Sources } \\
\hline & & A & B & $\mathrm{C}$ & $\mathbf{D}$ & $\mathbf{E}$ & A & B & C & D & E \\
\hline \multirow{4}{*}{ SD1 } & 0.025 & 0.79 & 3.78 & 0.19 & 0.40 & 0.36 & 1.86 & 29.95 & 0.07 & 0.46 & 0.40 \\
\hline & 0.5 & 19.68 & 43.62 & 5.07 & 10.28 & 9.39 & 29.77 & 46.08 & 2.65 & 9.75 & 8.03 \\
\hline & 0.975 & 69.01 & 80.18 & 23.73 & 45.16 & 41.93 & 53.92 & 71.78 & 10.59 & 29.91 & 26.64 \\
\hline & difference & 68.22 & 76.40 & 23.54 & 44.76 & 41.57 & 52.07 & 41.83 & 10.52 & 29.45 & 26.25 \\
\hline \multirow{4}{*}{ SD2 } & 0.025 & 0.79 & 3.55 & 0.20 & 0.41 & 0.37 & 2.80 & 28.42 & 0.09 & 0.46 & 0.29 \\
\hline & 0.5 & 19.73 & 42.36 & 5.24 & 10.73 & 9.72 & 30.04 & 44.71 & 2.81 & 10.25 & 8.22 \\
\hline & 0.975 & 68.88 & 79.46 & 24.23 & 45.69 & 43.15 & 53.49 & 68.95 & 11.29 & 32.59 & 28.04 \\
\hline & difference & 68.09 & 75.91 & 24.03 & 45.27 & 42.77 & 50.69 & 40.53 & 11.20 & 32.14 & 27.75 \\
\hline \multirow{4}{*}{ SD3 } & 0.025 & 0.80 & 3.36 & 0.20 & 0.43 & 0.39 & 2.89 & 25.40 & 0.15 & 0.56 & 0.47 \\
\hline & 0.5 & 20.15 & 41.71 & 5.37 & 10.78 & 9.76 & 29.57 & 41.39 & 3.16 & 11.85 & 9.19 \\
\hline & 0.975 & 69.03 & 78.90 & 24.65 & 46.13 & 43.38 & 53.42 & 66.15 & 13.09 & 34.58 & 30.31 \\
\hline & difference & 68.23 & 75.54 & 24.45 & 45.70 & 42.99 & 50.53 & 40.75 & 12.95 & 34.02 & 29.85 \\
\hline \multirow{4}{*}{ SD4 } & 0.025 & 0.76 & 4.23 & 0.18 & 0.37 & 0.33 & 2.08 & 27.31 & 0.10 & 0.47 & 0.26 \\
\hline & 0.5 & 19.24 & 46.09 & 4.73 & 9.66 & 8.84 & 29.91 & 44.13 & 3.06 & 9.76 & 8.33 \\
\hline & 0.975 & 68.93 & 81.63 & 22.59 & 43.05 & 40.44 & 56.04 & 68.60 & 11.89 & 31.55 & 26.76 \\
\hline & difference & 68.17 & 77.40 & 22.41 & 42.68 & 40.11 & 53.96 & 41.29 & 11.78 & 31.08 & 26.50 \\
\hline \multirow{4}{*}{ SD5 } & 0.025 & 0.72 & 4.70 & 0.17 & 0.35 & 0.33 & 1.33 & 30.51 & 0.05 & 0.40 & 0.24 \\
\hline & 0.5 & 18.87 & 47.45 & 4.57 & 9.42 & 8.58 & 30.05 & 47.19 & 2.63 & 8.96 & 7.27 \\
\hline & 0.975 & 68.52 & 82.32 & 21.93 & 42.58 & 39.79 & 54.64 & 70.99 & 10.50 & 28.00 & 25.09 \\
\hline & difference & 67.80 & 77.62 & 21.76 & 42.23 & 39.46 & 53.31 & 40.48 & 10.45 & 27.60 & 24.86 \\
\hline \multirow{4}{*}{ SD6 } & 0.025 & 0.74 & 4.37 & 0.18 & 0.38 & 0.35 & 1.84 & 31.05 & 0.14 & 0.46 & 0.35 \\
\hline & 0.5 & 18.86 & 46.52 & 4.73 & 9.68 & 8.86 & 29.46 & 47.47 & 2.88 & 8.71 & 7.30 \\
\hline & 0.975 & 68.65 & 81.89 & 22.57 & 43.08 & 40.48 & 53.37 & 72.33 & 10.75 & 29.46 & 26.81 \\
\hline & difference & 67.91 & 77.52 & 22.39 & 42.70 & 40.14 & 51.54 & 41.27 & 10.61 & 29.00 & 26.46 \\
\hline \multirow{4}{*}{ SD7 } & 0.025 & 0.73 & 4.45 & 0.17 & 0.38 & 0.33 & 2.08 & 30.81 & 0.08 & 0.36 & 0.24 \\
\hline & 0.5 & 18.89 & 46.53 & 4.66 & 9.73 & 8.84 & 31.54 & 46.82 & 2.81 & 8.75 & 7.12 \\
\hline & 0.975 & 68.43 & 81.94 & 22.36 & 43.38 & 40.53 & 53.97 & 70.82 & 11.02 & 29.23 & 25.02 \\
\hline & difference & 67.71 & 77.49 & 22.18 & 43.01 & 40.20 & 51.88 & 40.01 & 10.93 & 28.87 & 24.78 \\
\hline \multirow{4}{*}{ SD8 } & 0.025 & 0.63 & 3.27 & 0.16 & 0.33 & 0.29 & 3.48 & 26.08 & 0.15 & 0.54 & 0.35 \\
\hline & 0.5 & 17.33 & 49.02 & 4.43 & 8.67 & 7.94 & 31.11 & 42.69 & 2.99 & 10.39 & 8.93 \\
\hline & 0.975 & 66.75 & 86.50 & 27.74 & 45.16 & 42.81 & 55.28 & 66.22 & 12.53 & 33.44 & 27.79 \\
\hline & difference & 66.12 & 83.23 & 27.58 & 44.83 & 42.52 & 51.80 & 40.14 & 12.38 & 32.90 & 27.44 \\
\hline
\end{tabular}




\section{Discussion}

The measured data and the Basler method have shown that the maximum salinity is in the Salty polygon and salty and puffy terrains and the maximum salinity in the sand dunes has been identified especially in the wind shadow samples. These source terrains have played a major role in the salinization of the sand dunes. Therefore, the results have shown that the terrain sources have been located in the strongly saline $\left(>10^{3} \mathrm{mS} / \mathrm{cm}\right)$ terrain and consequently the sand dunes are also saline $\left(>10^{2} \mathrm{mS} / \mathrm{cm}\right)$. Also, research in the Qarhan Desert, China, showed that cohesion of saline sand when water was present increased the threshold shear velocity (Li et al. 2019). Drying of Urmia Lake over the past decade has created new, salty terrains on the exposed bed allowing fine particles of salt to be carried by the wind causing the sand dunes to become salty. Also, one study based on remote sensing found new dust sources for the period 2000-2017 in Urmia Lake (Boroughani et al. 2020). Through multi temporal image processing they tracked the effects of both dam construction and frequent droughts on the increasing of littoral dried area of the Lake and concluded that newly generated dust can affect a large area surrounding the lake (>100 km).

The results of normalizing the elements showed that the maximum of $\mathrm{As}, \mathrm{Sr}, \mathrm{Pb}$, Mo elements was a result of an acidic environment resulting from the oxidation of igneous rocks (Boroughani et al. 2020), dolomite, calcite, aragonite and gypsum, and high levels of $\mathrm{Cl}$ is due to salinity (Table. 2). The high levels of $\mathrm{Co}$ and $\mathrm{Ni}$ in potential sources is a result of being in a volcanic zone and close to industrial centers and residential areas. Also, the high presence of iron in the terminus of the fine sandy alluvial fan terrain is likely linked to agricultural activity and the use of pesticides (Boroughani et al. 2020).

In general, CIA values ranging from 80 to 100 imply that limited chemical weathering occurred under hot and humid conditions (Ding et al. 2016), but this study has shown that the maximum value of the CIA $(31.2 \%)$ is in the Clay, salty areas, puffy and flaky lands, mainly due to high clay presence, and puffy lands has a minimum value $(4.8 \%)$ due to high salt presence. Furthermore, CIA values decreased from the west to the east of the study area, which indicates that the western sediments are more sensitive to weathering than the eastern sediments.

The enrichment ratio of $\mathrm{CaO}(10-30 \%)$ is explained by a high level of calcite in all samples. Also, relationships between $\mathrm{Fe}_{2} \mathrm{O}_{3}$ and $\mathrm{Al}_{2} \mathrm{O}_{3}$ and between $\mathrm{Al}_{2} \mathrm{O}_{3}$ and $\mathrm{SiO}_{2}$ have been used to separate granite-derived soils from basalt-derived soils (Dyer et al. 1999) and generally coexist in soils (Taylor et al. 1985). The high concentration of these elements in the potential sources indicates a dominant contribution from weathering of acidic igneous and metamorphic rocks but the amount of these elements is low in all samples. This apparent contradiction may be a result of elements in the source sediments, which low energy prevailing winds $(\mathrm{DP}=63, \mathrm{UDI}=0.52)$ could not transport.

The maximum $\mathrm{Na}_{2} \mathrm{O}$ concentration is in the Salty and puffy lands (2.85\%), and is mainly due to the high evaporation of surface water and the presence of abundant salt. The maximum $\mathrm{K}_{2} \mathrm{O}$ in the clay, salty areas, puffy and flaky lands $(2.20 \%)$ is mostly due to the high presence of salt with clay. Also, in all terrains the maximum amount of $\mathrm{Fe}_{2} \mathrm{O}_{3}, \mathrm{Al}_{2} \mathrm{O}_{3}$ and $\mathrm{SiO}_{2}$ was associated with granite and gabbro. Boroughani et al. (2020) also stated that the presence of metamorphic and igneous rocks in the western uplands watersheds of the Lake can increase the presence of $\mathrm{Al}, \mathrm{Fe}$ and $\mathrm{SiO}_{2}$.

In general, the presence of the $\mathrm{Al}, \mathrm{Fe}$ and $\mathrm{SiO}_{2}$ may be attributed to the existence of igneous and metamorphic rocks in the catchment and their mineralization, a conclusion supported by the positive skewness index. The high content of these elements is due to the presence of naturally occurring pyroxene, amphibolite, mica, granite and magnetite rocks. Therefore, these natural elements do not threaten human health. Intense human, agricultural, and industrial activities have taken place in the 
area in the past few decades, leading to pollution by pesticides and other chemicals. These pollutants can be dangerous to humans and cause health problems.

Based on the distance between the dunes and the GMUs, the Salty and puffy lands terrain is the closest area and it is the most important source according to the tracers. Therefore, considering the importance of this terrain for the sand supply to the sand dunes, revegetation involving, for example, Nitratia schoberi, which is a salt-tolerant species could prevent the surface detachment of soil in this area (Jafari et al. 2019). This shrub and other hydro halophyte species could prevent desertification in the sand dune and source region (Li et al. 2016; Li et al. 2017; Zareian et al. 2018).

The clay, salty and abandoned lands terrain, despite being across the path of the prevailing winds and upwind of the dunes, has not played a role in the production of sediment for the sand dunes due to its long distance from the sand dunes and its stabilization by being built over.

The terminus of the fine sandy alluvial fan and clay, salty areas, puffy and flaky lands terrains are also susceptible to erosion by the prevailing wind, and windbreaks and enclosure of land have prevented fine particles from moving through these geomorphic terrains; and the same thing has happened in the salty and puffy lands terrain. Furthermore, in the terminus of the fine sandy alluvial fan terrain, biological planning, including the construction of biotic windbreaks including the planting of shrubs, has prevented the movement of sediment. Although the sand dunes were located in different locations (north and south of the region), the relative contribution of sand sources for all potential sources are similar over the study area, so the relative contributions from the potential sources are not significantly different regionally. However as mentioned before, the relative important of each source terrain is related to its area.

The Kolmogorov-Smirnov test revealed that the geochemical data deviate from a normal distribution (Reimann et al. 2000) and therefore for statistical analysis non-parametric tests should be applied. The positive skewness of chemical results can be used to address problems of mineralization and environmental pollution due to mineral alteration processes related to lithoclimatic conditions in contrast to human activities. Such processes may lead to either an increase or decrease in the concentration of elements (Reimann et al. 2005 quoted by Nazari samani et al. 2011). Generally, in the study area industrial and mining activities may have produced skewness in the data, along with the presence of igneous and metamorphic rocks in the upland watersheds of the lake.

Comparing the results of Bayesian and GLUE sourcing revealed that, although the results are not identical, both methods produced the same relative estimates of contributions. Salty and puffy lands (B) are the main source in both Bayesian and GLUE analysis. According to the results of the Bayesian method, the three most important GMUs that produce sand dune sediments are respectively: Salty and puffy lands-B (44.2\%), Salty polygon terrain-A (23.5\%), and terminus of the fine sandy alluvial fan-D $(13.2 \%)$. While the GLUE results indicate salty and puffy lands-B (45.8\%), Salty polygon terrain-A (30.9\%) and terminus of the fine sandy alluvial fan $-\mathrm{D}(10.8 \%)$. Therefore, the same pattern for sediment supply by GMU is observed. It is noticeable that the importance of each GMU as a source is dependent on their relative areas, and this will be discussed more in the following paragraph.

The results of the models show that the maximum contribution of sediments is from the salty and puffy lands and salty polygon terrain, but the exact values of the contributions are different. Unlike previous work (e.g., Gholami et al. 2019; Gholami et al. 2019), that used a Monte Carlo method, none of the applied methods provided a full uncertainty band range (0-100). But for the salty and puffy lands source both methods (GLUE and Bayesian methods) estimated a wide uncertainty band range in contrast to the other GMUs (Figure $7 \mathrm{~B}$ ). The main reason for this result is related to the effects of both drying of the saline surface of the Lake on one hand and the effect of loose and fine- 
grained salty sediments terrain on the other hand side related to haloturbation processes. In other word, the stracture of laminated salt surface can be complex due to evaporative crystallization of salt and therefore the surface properties of them have spatio-temporal variability (Reynolds et al. 2007).

Overall, across all sources and sediment samples the GLUE method estimated a narrower CI uncertainty bound that can be attributed to the structure of the model. In the GLUE method an important $\mathrm{Cl}$ tracer that has influenced the width of the uncertainty bound acts as a cutoff threshold that is used to identify behavioral parameter sets. This cutoff threshold is selected by the user and is inserted subjectively in the GLUE method. In the Bayesian method an uninformative distribution was used for the parameters. Incorporating prior knowledge and using an informative prior distribution can reduce estimated uncertainty. Cooper et al. (2015) Found that using a narrower hyper-parameter distribution can reduce estimated uncertainty associated with source contributions. Therefore, in the Bayesian method a multivariate distribution should be used to infer the posterior and can be used to model correlation between parameters better than GLUE. An example is the estimation of uncertainty from the WASMOD hydrological model by (Jin et al. 2010) where a lower threshold results in a wider uncertainty bound.5. Conclusions

\section{Conclusion}

In the western part of the newly exposed floor of Lake Urmia people are currently faced by an increasing area of sand dunes. These sand dunes have fine, loose salty and non-saline sediments. In some seasons of the year (especially in spring and summer) sand and dust are raised and moved far away from the dried lake floor, affecting the whole province. Also, the movement of dunes has created a serious threat to the economic, social, health, and environmental resources on the edge of the lake. Therefore, it is important to study the origin of the sand dunes to provide information to reduce their creation and mobility. In this paper, a Bayesian mixing model was used to fingerprint the sediment sources of the sand dunes. The aeolian sediment source tracing method has been successfully used to determine the relative importance of regional terrains as contributors to the dunes. The findings of this study are as follows: 1) In order to determine the relative contribution of sediments to the sand dunes of Urmia Lake, the potential sources have been classified into five Geomorphologic Map Units (GMU). 2- The Storm roses and sand rose graphs in the area have revealed that the prevailing and erosive winds blow from the West-South-West and the movement of sand dunes is therefore to the East-North East. 3) Geochemical results for all samples using XRF have been provided. 4). The CIA index has revealed that the study area is subject to very low rates of weathering because it is located in a zone of igneous rocks. 5) The enrichment ratio based on the upper continental crust revealed that elements in the sediments are enriched, because the environment is acidic. 6) The drying of Urmia Lake in recent decades has led to the emergence of saline and salt terrains which have played the most important role in the creation and salinity of the sand dunes. 7) The main elements used as tracers of the sand dune sediment sources, selected as the optimum composite tracers, and used in mixing models are: $\mathrm{Mo}, \mathrm{Na} 2 \mathrm{O}, \mathrm{S}$ and $\mathrm{Cl} .8$ ) The study of sediment tracing sources using a Bayesian mixing model shows that the largest contributions to the dunes are from the Salty and puffy lands (B) followed by the Salty polygon terrain(A). 9) Because of similar variation of tracer concentrations in both sources (Salty polygon and Salty and puffy lands) the Bayesian model results had large uncertainties for these GMUs. This result indicates that, although the use of salt content as an informative tracer can help the tracing of salty sand dunes, but use of salty ions can increase the uncertainty of the final quantitative results.10) Moreover, the wide uncertainty bound for two salty sources indicates that by increasing the number of tracers helps to separate geochemical chracateristics of the sources area, thereby reducing the uncertainty level. According to the findings, to understand the undesirable effects of a lake drawdown in a dry land environment, more examples are needed to better control deflation from the areas left after drying of the lake floor so that similar effects on the surrounding area of Urmia Lake are not repeated. 
Author Contributions: "Conceptualization, A.Nazari Samani and ; methodology, A. Fathabadi; software, A. Fathabadi, validation, A.Nazari Samani, A. Fathabadi; formal analysis , L.Biyabani; investigation, L.Biyabani; resources, H.Khosravi.; data curation, A.Nazari Samani.; writing-original draft preparation, L.Biyabani, writing-review and editing, R.J.Wasson.; visualization, M.Borji Hassangavyar.; supervision, A.Nazari Samani; project administration A.Nazari Samani;. All authors have read and agreed to the published version of the manuscript."

Acknowledgments: The authors would like to appreciate Mr. Behrooz Akbarpoor for all patiently supports during the field sampling.

Conflicts of Interest: The authors declare no conflict of interest

\section{References}

1. Adabi MH (2004) Geochemical of sediments. Iran, Arian zamin publisher.

2. AghaKouchak A, Farahmand A, Melton FS, Teixeira J, Anderson MC, Wardlow BD, et al. (2015) Remote sensing of drought: Progress, challenges and opportunities. Reviews of Geophysics 53: 452-80. https://doi.org/10.1002/2014RG000456.

3. Besler H (2011) The Great Sand Sea in Egypt: formation, dynamics and environmental change-a sedimentanalytical approach. Edited by A.J. VAN LOON. Elsevier.

4. Beven, K (200) A manifesto for the equifinality thesis. Journal of Hydrology 320: 18-36. https://doi.org/10.1016/j.jhydrol.2005.07.007.

5. Blasone R-S, Vrugt JA, Madsen H, Rosbjerg D, Robinson BA, Zyvoloski GA (2008) Generalized likelihood uncertainty estimation (GLUE) using adaptive Markov Chain Monte Carlo sampling. Advances in Water Resources 31: 630-48. doi.org/ 10.1016/j.advwatres.2007.12.003.

6. Boroughani M, Hashemi H, Hosseini SH, Pourhashemi S, Berndtsson R (2020) Desiccating Lake Urmia: A New Dust Source of Regional Importance. IEEE Geoscience and Remote Sensing Letters 17: 1483-87. 10.1109/LGRS.2019.2949132.

7. Carlin BP, Louis TA (1996) Identifying prior distributions that produce specific decisions, with application to monitoring clinical trials. Bayesian Analysis in Statistics and Econometrics: Essays in Honor of Arnold Zellneressays in honor of Arnold Zellner / Donald A. Berr.

8. Chappell A, Webb NP, Leys JF, Waters CM, Orgill S, Eyres MJ (2019) Minimising soil organic carbon erosion by wind is critical for land degradation neutrality. Environmental Science E Policy 93: 43-52. https://doi.org/10.1016/j.envsci.2018.12.020.

9. Collins AL, Walling DE (2002) Selecting fingerprint properties for discriminating potential suspended sediment sources in river basins. Journal of Hydrology 261: 218-44. https://doi.org/10.1016/S00221694(02)00011-2.

10. Collins AL, Walling DE, Webb L, King P (2010) Apportioning catchment scale sediment sources using a modified composite fingerprinting technique incorporating property weightings and prior information. Geoderma 155: 249-61. https://doi.org/10.1016/j.geoderma.2009.12.008.

11. Cooper RJ, Krueger T, Hiscock KM, Rawlins BG (2015) High-temporal resolution fluvial sediment source fingerprinting with uncertainty: A Bayesian approach. Earth Surface Processes and Landforms 40: 78-92. https://doi.org/ 10.1002/esp.3621.

12. Ding H, Ma D, Yao C, Lin $Q$, Jing L (2016) Implication of the chemical index of alteration as a paleoclimatic perturbation indicator: an example from the lower Neoproterozoic strata of Aksu, Xinjiang, NW China. Geosciences Journal 20: 13-26. https://doi.org/ 10.1007/s12303-015-0025-2.

13. Dotto CB, Mannina G, Kleidorfer M, Vezzaro L, Henrichs M, McCarthy DT, et al (2012) Comparison of different uncertainty techniques in urban stormwater quantity and quality modelling. Water research 46 : 2545-58. https://doi.org/ 10.1016/j.watres.2012.02.009.

14. Douglas G, Caitcheon G, Palmer M (2009) Sediment source identification and residence times in the Maroochy River estuary, southeast Queensland, Australia. Environmental Geology 57: 629-39. https://doi.org/ 10.1007/s00254-008-575 1336-7.

15. Dyer F, Olley J, Moore G, Murray A (1999) Sources of sediment and phosphorus in tarago reservoir. Water 26: 11-12.

16. Franks SW, Rowan JS (2000) Multi-parameter fingerprinting of sediment sources: uncertainty estimation and tracer selection. Computational methods in water resources 13: 1067-74.

17. Gholami H, Middleton N, Samani AAN, Wasson R (2017) Determining contribution of sand dune potential sources using radionuclides, trace and major elements in central Iran. Arabian Journal of Geosciences 10: 163. https://doi.org/ 10.1007/s12517-017-2917-0. 
18. Gholami H, TakhtiNajad EJ, Collins AL, Fathabadi A (2019) Monte Carlo fingerprinting of the terrestrial sources of different particle size fractions of coastal sediment deposits using geochemical tracers: some lessons for the user community. Environmental Science and Pollution Research 26: 13560-79. https://doi.org//10.1007/s11356-019-04857-0.

19. Honda M, Yabuki S, Shimizu H (2004) Geochemical and isotopic studies of aeolian sediments in China. Sedimentology 51: 211-30. https://doi.org/10.1046/j.1365-3091.2003.00618.x.

20. Jafari Takhtinajad E, Gholami H, Collins A, Fathabadi A (2019) Identifying and Quantifying the Terrestrial Sediment Source Contributions to Coastal Dunes for Targeting Wind Erosion Mitigation in Jagin Watershed, Hormozgan Province, Iran. Watershed Management Researches Journal 32: 3-18. https://doi.org/1810.22092/wmej.2019.123109.1142.

21. Jin X, Xu C-Y, Zhang Q, Singh V (2010) Parameter and modeling uncertainty simulated by GLUE and a formal Bayesian method for a conceptual hydrological model. Journal of Hydrology 383: 147-55. https://doi.org/10.1016/j.jhydrol.2009.12.028.

22. Kasper-Zubillaga J, Zolezzi-Ruíz H, Carranza-Edwards A, Girón-García P, Ortiz-Zamora G, Palma M (2007) Sedimentological, modal analysis and geochemical studies of desert and coastal dunes, Altar Desert, NW Mexico. Earth Surface Processes and Landforms: The Journal of the British Geomorphological Research Group 32: 489-508. https://doi.org/10.1002/esp.1402.

23. Katebi H, Fahmi A, Samadi Kafil H, Hajialilue Bonab M (2018) Stabilization of calcareous sand dunes using phosphoric acid mulching liquid. Journal of Arid Environments 148: 34-44. doi.org/10.1016/j.jaridenv.2017.09.011.

24. Li C, Dong Z, Yin S, Chen G, Yang J (2019) Influence of salinity and moisture on the threshold shear velocity of saline sand in the Qarhan Desert, Qaidam Basin of China: A wind tunnel experiment. Journal of Arid Land 11: 674-84. https://doi.org/ 0.1016/j.catena.2016.09.005. .

25. Li Q, Zhang C, Shen Y, Jia W, Li J (2016) Quantitative assessment of the relative roles of climate change and human activities in desertification processes on the Qinghai-Tibet Plateau based on net primary productivity. Catena 147: 789-96. https://doi.org10.1016/j.ijsrc.2017.02.003.

26. Li Y, Li Z, Wang Z, Wang W, Jia Y, Tian S (2017) Impacts of artificially planted vegetation on the ecological restoration of movable sand dunes in the Mugetan Desert, northeastern Qinghai-Tibet Plateau. International Journal of Sediment Research 32: 277-87. https://doi.org/10.1007/s40333-019-0058-x.

27. Mabit L, Gibbs M, Mbaye M, Meusburger K, Toloza A, Resch C, et al (2018) Novel application of Compound Specific Stable Isotope (CSSI) techniques to investigate on-site sediment origins across arable fields. Geoderma 316: 19-26. https://doi.org/10.1016/i.geoderma.2017.12.008.

28. Martínez-Carreras N, Krein A, Udelhoven T, Gallart F, Iffly JF, Hoffmann L, et al (2010) A rapid spectral-reflectance-based fingerprinting approach for documenting suspended sediment sources during storm runoff events. Journal of Soils and Sediments 10: 400-13. https://doi.org/ 10.1007/s11368-0090162-1.

29. McLennan SM (1993) Weathering and Global Denudation. The Journal of Geology 101: 295-303. https://doi.org//10.1086/648222.

30. Motha JA, Wallbrink PJ, Hairsine PB, Grayson RB (2003) Determining the sources of suspended sediment in a forested catchment in southeastern Australia. Water resources research 39. https://doi.org/10.1029/2001wr000794.

31. Nazari Samani A, Biabani L, Abbasi H, Khosravi H (2011) Application of multiple sediment fingerprinting techniques to determine the sediment source contribution of gully erosion: Review and case study from Boushehr province, southwestern Iran. Progress in Physical Geography 35: 375-91. https://doi.org/10.1177/0309133311401643.

32. Nazari Samani A, Wasson RJ, Malekian A (2018) Effects of wind erosivity and sand drift on the littoral area of Urmia Lake and sand mobility. Iranian Journal of Range and Desert Research 25.

33. Reimann C, Filzmoser P (2000) Normal and lognormal data distribution in geochemistry: death of a myth. Consequences for the statistical treatment of geochemical and environmental data. Environmental Geology 39: 1001-14. https://doi.org/10.1007/s002549900081.

34. Reimann C, Filzmoser P, Garrett RG (2005) Background and threshold: critical comparison of methods of determination. Science of the total environment 346: 1-16. https://doi.org/10.1016/j.scitotenv.2004.11.023.

35. Reynolds RL, Yount JC, Reheis M, Goldstein H, Chavez Jr P, Fulton R, et al (2007) Dust emission from wet and dry playas in the Mojave Desert, USA. Earth Surface Processes and Landforms: The Journal of the British Geomorphological Research Group 32: 1811-27. 10.1002/esp.1515.

36. Saye SE, Pye K (2006) Variations in chemical composition and particle size of dune sediments along the west coast of Jutland, Denmark. Sedimentary Geology 183: 217-42. https://doi.org/10.1016/j.sedgeo.2005.09.011. . 
37. Shen Z, Chen L, Chen T (2012) Analysis of parameter uncertainty in hydrological and sediment modeling using GLUE method: a case study of SWAT model applied to Three Gorges Reservoir Region, China. Hydrology and Earth System Sciences 16: 121-32. https://doi.org/ 10.5194/hess-16-121-2012.

38. Skidmore EL (2000) Air, soil, and water quality as influenced by wind erosion and strategies for mitigation. In Second International Symposium of New Technologies for Environmental Monitoring and AgroApplications Proceedings (pp. 216-221).

39. Small IF, Rowan JS, Franks SW (2002) Quantitative sediment fingerprinting using a Bayesian uncertainty estimation framework. International Association of Hydrological Sciences, Publication 276: 44350.

40. Stewart HA, Massoudieh A, Gellis A (2015) Sediment source apportionment in Laurel Hill Creek, PA, using Bayesian chemical mass balance and isotope fingerprinting. Hydrological Processes 29: 2545-60. https://doi.org/10.1002/hyp.10364.

41. Taylor SR, McLennan SM (1985) The continental crust: its composition and evolution.

42. Vrugt JA, Ter Braak CJ, Gupta HV, Robinson BA (2009) Equifinality of formal (DREAM) and informal (GLUE) Bayesian approaches in hydrologic modeling? Stochastic environmental research and risk assessment 23: 1011-26. https://doi.org//10.1007/s00477-008-0274-y.

43. Walling DE (2005) Tracing suspended sediment sources in catchments and river systems. Science of the total environment 344: 159-84. https://doi.org/10.1016/j.scitotenv.2005.02.011.

44. Walling DE (2013) The evolution of sediment source fingerprinting investigations in fluvial systems. Journal of Soils and Sediments 13: 1658-75. https://doi.org/ 722 10.1007/s11368-013-0767-2.

45. Wang X, Xia D, Zhang C, Lang L, Hua T, Zhao S (2012) Geochemical and magnetic characteristics of fine-grained surface sediments in potential dust source areas: implications for tracing the provenance of Aeolian deposits and associated palaeoclimatic change in East Asia. Palaeogeography, Palaeoclimatology, Palaeoecology 323: 123-32. https://doi.org/10.1016/j.palaeo.2012.02.005.

46. Yu D, Yin J, Liu M (2016) Validating city-scale surface water flood modelling using crowd-sourced data. Environmental Research Letters 11: 124011. https://doi.org/10.1088/17489326/11/12/124011.

47. Zareian F, Jafari M, Javadi SA, Tavili A (2018) Application of zeolite and geohumus superabsorbent on establishment and some growth indices of Nitraria schoberi L. Acta Ecologica Sinica 38: 296-301. https://doi.org/10.1016/j.chnaes.2017.12.005.

\section{Statements \& Declarations:}

The authors declare that no funds, grants, or other support were received during the preparation of this manuscript. The authors have no relevant financial or non-financial interests to disclose. 